\title{
Expressed Emotions among Caregivers of Patients with Mental Illness: A Descriptive Study
}

\author{
Mrs. Bharati Suresh Batra ${ }^{1}$, Dr.Rakesh Ghildiyal ${ }^{2}$, Dr. Anand Milind Saoji ${ }^{3}$ \\ ${ }^{\prime}$ (Ph.D. Scholar, MGMIHS, Navi Mumbai India.) \\ ${ }_{2}^{2}$ (Professor and Head, Department Of Psychiatry, MGMIHS, Navi Mumbai-410209 India) \\ ${ }^{3}$ (Associate Professor, Department Of Psychiatry, Indira Gandhi Government \\ Medical College and Hospital Nagpur-440018 India)
}

\begin{abstract}
Aim \& Objectives: The present study attempts to assess the level of expressed emotions prevailing among the caregivers of inpatients with mental illness in a general hospital psychiatric set up at Government Medical College and Hospital Nagpur by quantification.

Background: Expressed Emotion (EE) refers to caregivers' attitude towards a person with a mental disorder as reflected by comments about the patient made to an interviewer. Expressed Emotion is a significant characteristic of the family milieu that has been found to predict symptom relapse in a wide range of mental disorders.
\end{abstract}

Design and method: This study followed a quantitative approach with descriptive survey research design and recruited 100 caregivers of patients with mental illness admitted in psychiatric inpatient department of Government Medical College and Hospital Nagpur by purposive sampling technique with inclusion and exclusion criteria. The criteria for inclusion of caregivers were caregivers of patients with diagnosis of schizophrenia and bipolar disorder by ICD-10 or DSM IV-TR criteria with history of relapse and readmission and dependent on caregivers for their Activities of daily living (ADL) and medication compliance. Total duration of illness with patient 1 Year -10 years. Age of caregivers being 18 to 65 years. Can be a parent, spouse, sibling, child or other relative, having maximum hours of contact with the patient. Caregivers with chronic medical or psychiatric illness and those taking care of any other patient with disability and having language incompatibility were excluded from the study. Ethical approval and permission for the study was obtained from the competent authority of the institute. Permission taken from Institutional review board. An informed consent from the caregivers of the patients was taken. Assurance of confidentiality and freedom to dropout from the study as and when they wish to do so was ascertained.

Instruments : The instruments used were Socio- demographic data sheet \& clinical data sheet of patients for inclusion in study. Socio- demographic data sheet of caregivers. (FEICS) Family Emotional Involvement and Criticism Scale (Shield et .al. 1992) was selected to quantify the (PC) Perceived Criticism and (EI) Emotional Involvement in the family.

Scoring the FEICS: The PC is assessed by even numbered items and EI is measured by odd number items on 5 point Likert type scale which includes response options of almost never, once in a while, sometimes, often, almost always. On this scale high scores indicate greater levels of PC \& EI.The subscale scores were also categorized as mild, moderate and severe level of EE.

Observations and results: Mean age of the patients was 33.29 years where as the caregiver's mean age was 42.07years. Majority of the patients (51\%) and caregivers (65\%) were female. Most of the patients (56\%) and caregivers (81\%) were married. Many of the patients (60\%) and caregivers (60\%) belong to nuclear family. Majority of the patients and caregivers (52\%) were from urban area. Majority of the patients and caregivers $(82 \%)$ were Hindus. Most of the patients and caregivers were from lower middle income group. All the patients (100\%) had social support and daily contact with caregivers. Majority of the patients (70\%) were diagnosed as schizophrenia. The maximum duration of illness was 10 years and minimum duration of illness was 1 year.

FEICS Score: The mean Perceived Criticism (PC) score of the caregivers on FEICS was 29 out of 35 and Mean Emotional Involvement (EI) score was 28.98 out of 35.The total mean score of the caregivers of patients with mental illness was 58.12 which shows high Expressed Emotions (EE) among caregivers. There was no significant association found between the selected demographic variable of caregivers and Expressed Emotions $(E E)$.

Conclusion: The overall findings of this study shows that the simple measures of Expressed Emotions (EE), Perceived Criticism (PC) and Emotional Involvement (EI) score is high among the caregivers of patients with mental illness. There is complex circular relationship between Expressed Emotions (EE) and relapse, with the patient's behavior leading to changes in the relative's Expressed Emotions (EE) and the relatives' EE in turn affecting the course of the patient's illness like many other environmental stressors. Expressed Emotions may 
represent the circumstances of the relationship between patient and caregiver. The increased score on EE score suggests that psycho social interventions are needed for caregivers of patients with mental illness with high EE.

Keywords: Caregivers of patients with mental illness, Expressed Emotions (EE), Schizophrenia, Bipolar disorder.

\subsection{Background}

\section{Introduction}

The Expressed Emotion (EE) is considered to be an adverse family environment which includes the quality of interaction pattern and nature of family relationships among the family caregivers and patients with schizophrenia and other psychiatric disorders. ${ }^{1}$

The ability of the family caregiver to provide quality care and contribute to the management of chronic disease is a vital health care resource. Health care providers should be supportive of family caregivers and help them acquire knowledge and problem solving, organizational and communication skills in order to maximize quality care. Some caregivers are able to carry out care giving tasks better than others because of their knowledge about the disease, their experience, level of involvement and skills. ${ }^{2}$

The Expressed Emotion (EE) is considered to be an adverse family environment which includes the quality of interaction pattern and nature of family relationships among the family caregivers and patients with schizophrenia and other psychiatric disorders. It is a significant characteristic of the family milieu that has been found to predict symptom relapse in a wide range of mental disorders. Relative of patients experience a range of emotions from loss and grief to guilt and anger. Like the patient, they also feel isolated and stigmatized. Their lives are disrupted by providing more care than would normally be appropriate for someone of the patients' age. The addition of the care giving role to already existing family roles become stressful- psychologically as well as economically. ${ }^{1,3 .}$

Available data show that the proportion of persons with schizophrenia living with their relatives ranges between 40 percent in the United States to more than 90 percent in China. The fact that in India over 90\% of those who are mentally ill live with their families and are dependent on them has led to research into family burden, family interventions, Expressed Emotions, and more recently into support groups. The recognition of the importance of families has led to the creation of facilities for families to stay with patients in some centers, such as the NIMHANS at Bangalore, and CMC at Vellore. This facilitates the extensive participation of families in therapeutic programmes. ${ }^{4}$

\subsection{Need of the Study}

There is high prevalence of psychiatric morbidity (18-20/1000) among general population. National Mental Health policy is emphasizing de-institutionalization of patients. There is lot of ignorance and misconceptions among the care givers of patients with schizophrenia causing relapse, readmission and revolving door phenomena. ${ }^{5}$

One of the consequences of the deinstitutionalization movement in the west has been the engagement of the family as the primary locus of the care for the mentally ill relative. However, from the Indian background, families have traditionally played the role of caregivers of their mentally ill relatives. They are recognized as having a prominent role to play in decisions regarding engagement or disengagement from the treatment process, supervision of medication, providing day to day care and emotional support. ${ }^{6}$.

Families are often on the front lines of care for persons with schizophrenia. The role of a long term caregiver is accompanied by many burdens and family members are left emotionally depleted and desperate for help. They need support to best assist their ill family member and to cope with the stress associated with

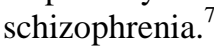

With de-institutionalization being practiced in the present mental health set up, the family members became the primary caregivers. Thus the burden on them increases thereby affecting their quality of life, coping strategy and their expressed emotion as well. Lack of knowledge about the schizophrenia causes fear and anxieties among the caregivers in managing their family member as well as increasing the burden faced by the families. ${ }^{8}$

This research study is significant in the context of current status of mental health services in India especially in a government hospital setup of Maharashtra.

\subsection{Conceptual and Theoretical Framework: Stress Vulnerability Model}

This study is based on the 'Stress Vulnerability Model', the most popular model used to explain psychosis which involves three factors. 


\section{Vulnerability Factors.}

This refers to the biological factors which predispose an individual to develop psychosis. The exact explanation for this biological vulnerability remains unclear, but it may be linked to genetic factors.

\section{Environmental Factors.}

In conjunction with vulnerability factors, these influence the onset and course of the symptoms. Living in an environment where there is a great deal of conflict, criticism or negativity may contribute to psychosis. Use of drugs such as Speed or Cannabis may also be contributing factors for some individuals.

Stressors that may trigger episodes of psychosis include accumulation of day to day hassles in an individual's life or more specific life events such as the death of someone close, a relationship breakdown, a change in residence or the loss of a job, etc.

According to the stress vulnerability model, psychosis emerges when stress exceeds an individual's 'vulnerability threshold'. There is currently no way of predicting what an individual's threshold is.

In this study the high Expressed emotions of the caregivers and negative atmosphere at the home is assumed to influence the recovery of the patient.

\section{Protective Factors.}

These act as a buffer against the effects of stress and biochemical vulnerabilities or help minimize the severity of symptoms. A key protective factor may be medication; other protective factors include stress management, social support and effective problem solving skills, etc.

In this study the family support and understanding of family members is assumed to be a protective factor for the patients. ${ }^{9}$

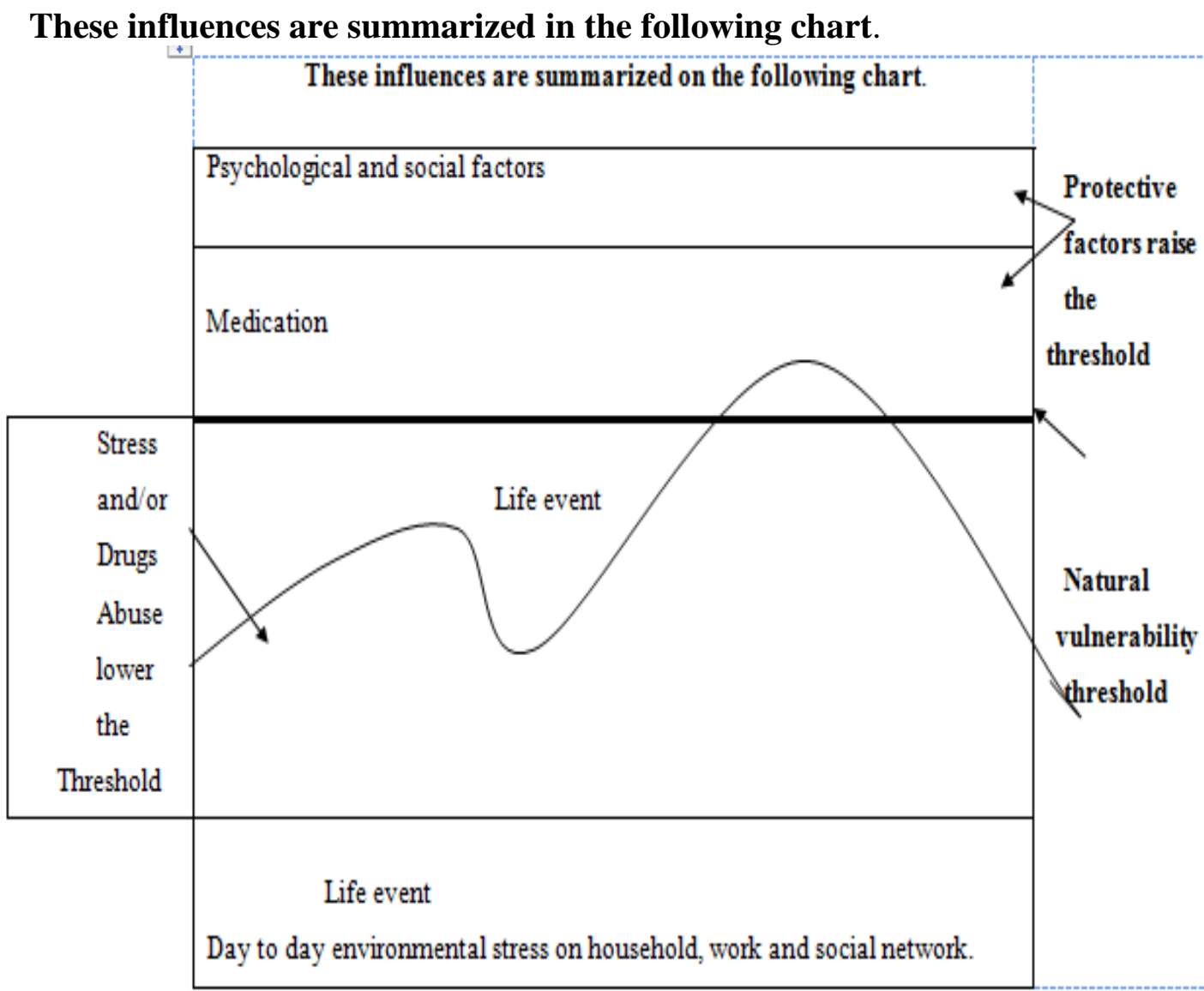

FIGURE: 1 STRESS|VULNERABILITY MODEL

Figure: 1 Stress Vulnerability Model 
Flow Chart of Methodology

\section{Method}

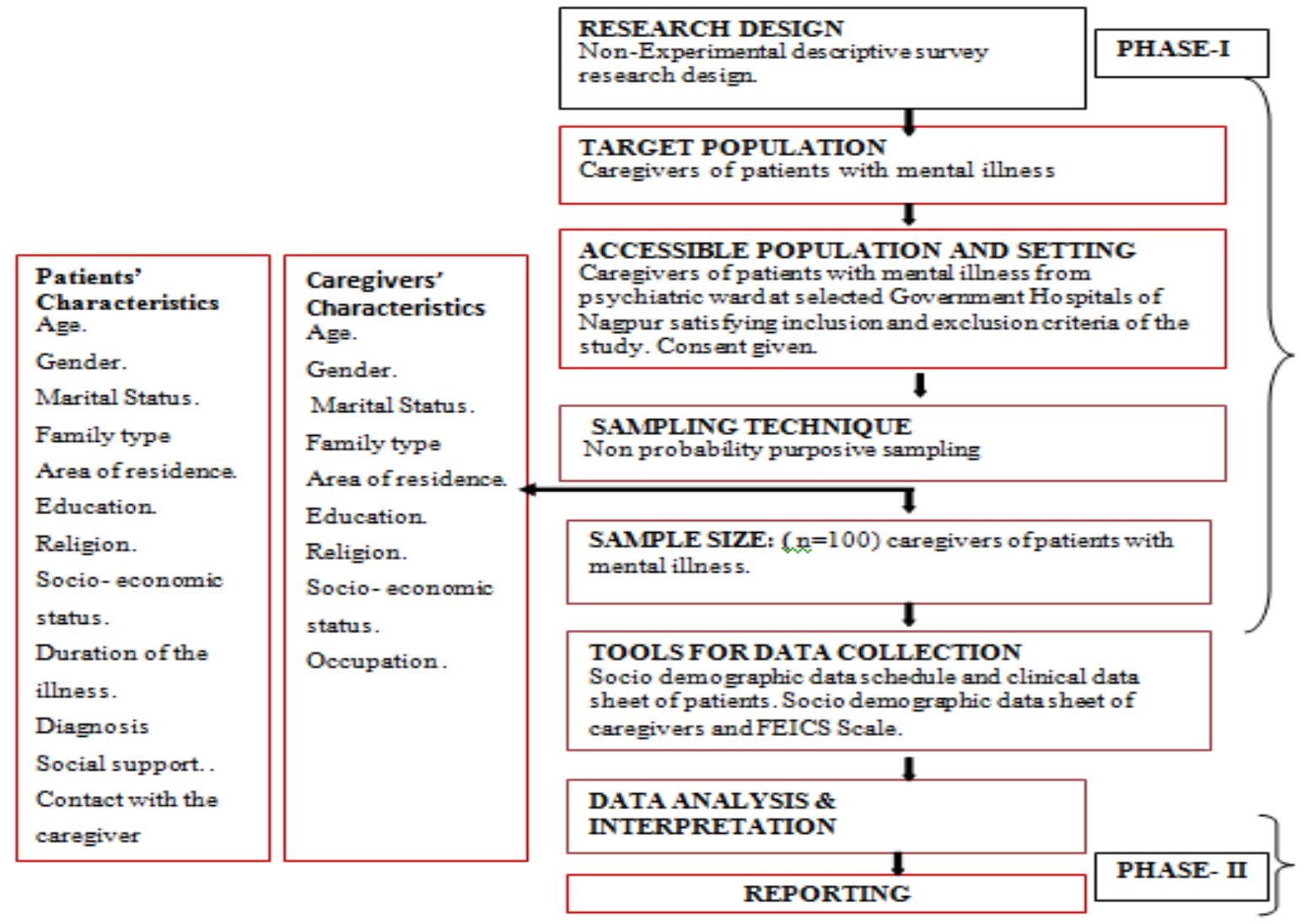

Figure 2: flow chart of research methodology

This study followed a quantitative approach with descriptive survey research design and recruited 100 caregivers of patients with mental illness admitted in psychiatric inpatient department of Government Medical College and Hospital Nagpur by purposive sampling technique with inclusion and exclusion criteria. Caregivers were defined as family members actively providing day-to-day-care for a person with the inclusion and exclusion criteria. Caregivers of patients also had no history of physical, psychological, or neurological problems and did not serve as caregivers for any other individual with any type of disability.

2.1 Research Approach: Quantitative Approach.

2.2 Research Design: Non-Experimental descriptive survey research design.

2.3 Variables under Study: Expressed Emotions of caregivers. (EE)

2.4 The Setting of the Study: The General Hospital psychiatric inpatient department of selected Government Hospitals of Nagpur, India.

\subsection{Participants}

The criteria for inclusion of caregivers were: Caregivers of patients with diagnosis of schizophrenia and bipolar disorder by ICD- 10 or DSM IV -TR criteria, with history of relapse and readmission and dependent on caregivers for their Activities of daily living (ADL) and medication compliance. Total duration of illness with patient 1 Year -10 years. Age 18 to 65 years. Can be a parent, spouse, sibling, child or other relative, having maximum hours of contact with the patient. Willing to participate in the study. Caregivers with chronic medical or psychiatric illness, taking care of any other patient with disability and having language incompatibility were excluded from the study. 


\subsection{Procedure}

After getting consent to participate in the study, caregivers were assessed individually in a private booth via a self-report questionnaire and an interview in selected government hospitals of Nagpur. 150 caregivers of patients with schizophrenia and bipolar disorder were initially approached in psychiatric ward and 100 agreed to participate (acceptance rate $=66.67 \%$ ).

\subsection{Data collection}

The data collected included the following:

1. Socio-demographic characteristics of the patients with mental illness: Age, Gender, Marital Status, Family type, Area of residence, Education, Religion, Socio- economic status, Duration of the illness, Diagnosis,Social support, Contact with the caregiver.

2. Socio-demographic characteristics of the caregivers: Age, Gender, Marital Status, Family type, Area of residence, Education, Religion, Socio- economic status, Occupation.

3. Assessment of Expressed Emotions by Family Emotional involvement and criticism Scale. (FEICS by Shield et .al. 1992)

\subsection{Data collection instruments}

Socio- demographic data sheet \& clinical data sheet of patients for inclusion in study.

Socio- demographic data sheet of caregivers.

Family Emotional involvement and criticism Scale (FEICS by Shield et .al. 1992) was selected to quantify the Perceived criticism (P C) and Emotional involvement (EI) in the family. This is a 14 item scale on which the items are then clubbed to derive two subscales: Perceived Criticism (PC) and Intensity of Emotional Involvement (El). Both the scales have 7 items each and are scored on a Likert scale ranging from 1-5 (minimum 7 to a maximum of 35 on each scale). Cronbach's alpha for both the subscales was $0.74-0.82$. Confirmatory factor analysis showed that each item loaded on its proposed factor and not with the other factor. The subscales exhibited correlations and partial correlations with various scales.

It is important to address the EI and criticism when working on families with member who has severe and persistent mental illness. Higher criticism and over involvement scores are associated with more mental healthcare visits to hospitals for biomedical and psychosocial services due to higher rates of relapses. This scale proposes that EE is an important variable in assessing and treating both biopsychological distresses. On 14-item scale, the PC subscale should clearly indicate negative attitudes and EI scale clearly reveal high levels of emotional involvement.

\subsection{Scoring of the FEICS:}

The $\mathrm{PC}$ is assessed by even numbered items and EI is measured by odd number items on 5 point Likert type scale. It includes response options of almost never, once in a while, sometimes, often, almost always. On this scale high scores indicate greater levels of PC \& EI. ${ }^{10}$ The FEICS total sub scale scores were also categorized as mild (0 to11), moderate (12-23) and severe (24-35).

\subsection{Ethical Consideration}

Written permission from the administrative authority of the hospital. Permission from Institutional review board. An informed consent from the caregivers of the patients. Assurance of confidentiality was given. Freedom to dropout from the study as and when they wish to do so was conveyed.

\section{Data Analysis}

Data of 100 completed forms was analyzed using SPSS 17.0 Statistical software. Data was presented using graphs and descriptive statistics such as mean, mode, median and Standard deviation. Associations between FEICS scores and continuous variables or categorical variables were analyzed using Pearson's correlation and Chi-squared test. The level of significance was set at 0.05 . All $\mathrm{p}$ values less than 0.05 were treated as significant.

\section{Observations and Results}

Section-I: Socio demographic details of patients and caregivers

\begin{tabular}{|c|c|c|c|}
\hline \multicolumn{4}{|c|}{ Table-1:Demographic characteristics of patients } \\
\hline Variables & & Frequency & $\%$ \\
\hline Age (Mean) & Mean years $(+\mathrm{SD})$ & $33 . .29(10.69)$ & \\
\hline Gender & Female & 51 & $51 \%$ \\
\hline & Male & 49 & $49 \%$ \\
\hline Marital Status & Married & 56 & $56 \%$ \\
\hline & Unmarried & 34 & $34 \%$ \\
\hline
\end{tabular}


Expressed Emotions Among Caregivers Of Patients With Mental Illness: A Descriptive Study

\begin{tabular}{|l|l|r|r|}
\hline & Widow/Widower & 2 & $2 \%$ \\
\hline & Separated & 8 & $8 \%$ \\
\hline Family Type & Nuclear & 60 & $60 \%$ \\
\hline & Joint & 40 & $40 \%$ \\
\hline Area of residence & Urban & 52 & $52 \%$ \\
\hline & Rural & 40 & $40 \%$ \\
\hline Education & Semi urban & 8 & $8 \%$ \\
\hline & Non Literate & 0 & $0 \%$ \\
\hline & Primary & 75 & $75 \%$ \\
\hline & Secondary & 15 & $15 \%$ \\
\hline & Graduate & 10 & $10 \%$ \\
\hline Religion & Above & 0 & $0 \%$ \\
\hline & Hindu & 82 & $82 \%$ \\
\hline & Boudha & 12 & $12 \%$ \\
\hline & Christian & 1 & $1 \%$ \\
\hline SES & Muslim & 5 & $5 \%$ \\
\hline & Lower Middle & 45 & $45 \%$ \\
\hline & Middle & 1 & $1 \%$ \\
\hline & Upper Middle & 13 & $13 \%$ \\
\hline & Upper & 5 & $5 \%$ \\
\hline & Upper Lower & 36 & $36 \%$ \\
\hline Duration of illness & Lower & 0 & $0 \%$ \\
\hline & 1 year-5yrs & 40 & $40 \%$ \\
\hline Diagnosis & 6years-10 years & 60 & $60 \%$ \\
\hline & Bipolar disorder & 30 & $30 \%$ \\
\hline Social support & Schizophrenia & 70 & $70 \%$ \\
\hline & Primary Caregivers & 100 & $100 \%$ \\
\hline Contact with the patient & Secondary caregivers & 0 & $0 \%$ \\
\hline & Daily & 100 & $100 \%$ \\
\hline & Weekly 3-4 times & 0 & $0 \%$ \\
\hline & Monthly & 0 & $0 \%$ \\
\hline & & &
\end{tabular}

\subsection{Major Findings of Table -1:}

The demographic details of 100 patients with mental illness are presented in Table-1. Majority of the patients $(51 \%)$ were female. Majority of patients $(56 \%)$ were married. Most of the patients $(60 \%)$ were from nuclear family. Many of the patients (52\%) were from urban area. Majority of the patients (75\%) had primary level of education. Most of the patients (82\%) were Hindu. Most of them (45\%) were from lower middle income group. Mean age of the patients was 33.29 ( $\mathrm{SD} \pm 10.69)$, with maximum age of 70 years and minimum age of 17 years. Duration of illness was ranging between 1 to 10 years. Majority of the patients (70\%) had diagnosis of schizophrenia. All the patients $(100 \%)$ received social support by their primary caregivers. Daily contact of patient with their caregivers was $100 \%$.

\begin{tabular}{|l|l|r|r|}
\multicolumn{5}{|c|}{ Table-2:Demographic characteristics of caregivers } \\
\hline Variables & \multicolumn{1}{c|}{ n=100 } \\
\hline Age (Mean) & Mean years (․SD) & $42.07(12.99)$ & \% \\
\hline Gender & Female & 65 & $65 \%$ \\
\hline & Male & 35 & $35 \%$ \\
\hline Marital Status & Married & 81 & $81 \%$ \\
\hline & Unmarried & 12 & $12 \%$ \\
\hline & Widow & 7 & $7 \%$ \\
\hline Family Type & Nuclear & 54 & $54 \%$ \\
\hline & Joint & 46 & $46 \%$ \\
\hline Area of residence & Urban & 52 & $52 \%$ \\
\hline & Rural & 48 & $48 \%$ \\
\hline Education & Non Literate & 15 & $15 \%$ \\
\hline & Primary & 43 & $43 \%$ \\
\hline & Secondary & 15 & $15 \%$ \\
\hline & Graduate & 20 & $20 \%$ \\
\hline & Above & 7 & $7 \%$ \\
\hline Religion & Hindu & 82 & $82 \%$ \\
\hline & Boudha & 12 & $12 \%$ \\
\hline & Christian & 1 & $1 \%$ \\
\hline & Muslim & 5 & $5 \%$ \\
\hline SES & Lower Middle & 45 & $45 \%$ \\
\hline & Middle & 1 & $1 \%$ \\
\hline & Upper Middle & 13 & $13 \%$ \\
\hline
\end{tabular}




\begin{tabular}{|r|l|r|r|} 
& Upper & 5 & $5 \%$ \\
\hline & Upper Lower & 36 & $36 \%$ \\
\hline & Lower & 0 & $0 \%$ \\
\hline \multirow{3}{*}{ Occupation } & Profession & 5 & $5 \%$ \\
\cline { 2 - 4 } & Semi-Profession & 0 & $0 \%$ \\
\cline { 2 - 4 } & Clerical, Shop-owner & 19 & $19 \%$ \\
\hline & Skilled worker & 6 & $6 \%$ \\
\hline & Semi-skilled worker & 6 & $6 \%$ \\
\hline & Unskilled worker & 9 & $9 \%$ \\
\hline & Unemployed & 55 & $55 \%$ \\
& /Homemaker & & \\
\hline
\end{tabular}

\subsection{Major Findings of the Table-2:}

Majority of the caregivers (65\%) were females. Most of the caregivers $(81 \%)$ were married \& many of the caregivers $(56 \%)$ were from nuclear family. Majority of the caregivers $(52 \%)$ were from urban area. Majority of the caregivers (43\%) had primary level of education. Majority of the caregivers (82\%) were Hindus. Many of the caregivers (45\%) were from lower middle income group. Most of the caregivers $(55 \%)$ were unemployed and homemakers. The mean age of caregivers was 42.07 with maximum age of 60 years and minimum age of 20 years.

Section II: FEICS Score of the caregivers

\begin{tabular}{|c|c|c|c|}
\hline & $\begin{array}{c}\text { PC } \\
\text { Max Score 35 }\end{array}$ & $\begin{array}{c}\text { EI } \\
\text { Max Score 35 }\end{array}$ & $\begin{array}{c}\text { TOTAL Score } \\
\text { Max Score 70 }\end{array}$ \\
\hline FEICS Score & Mean Score & Mean Score & Mean Score \\
\hline & 29 & 28.98 & 58.12 \\
\hline
\end{tabular}

Table -3: FEICS Score of the caregivers $n=100$

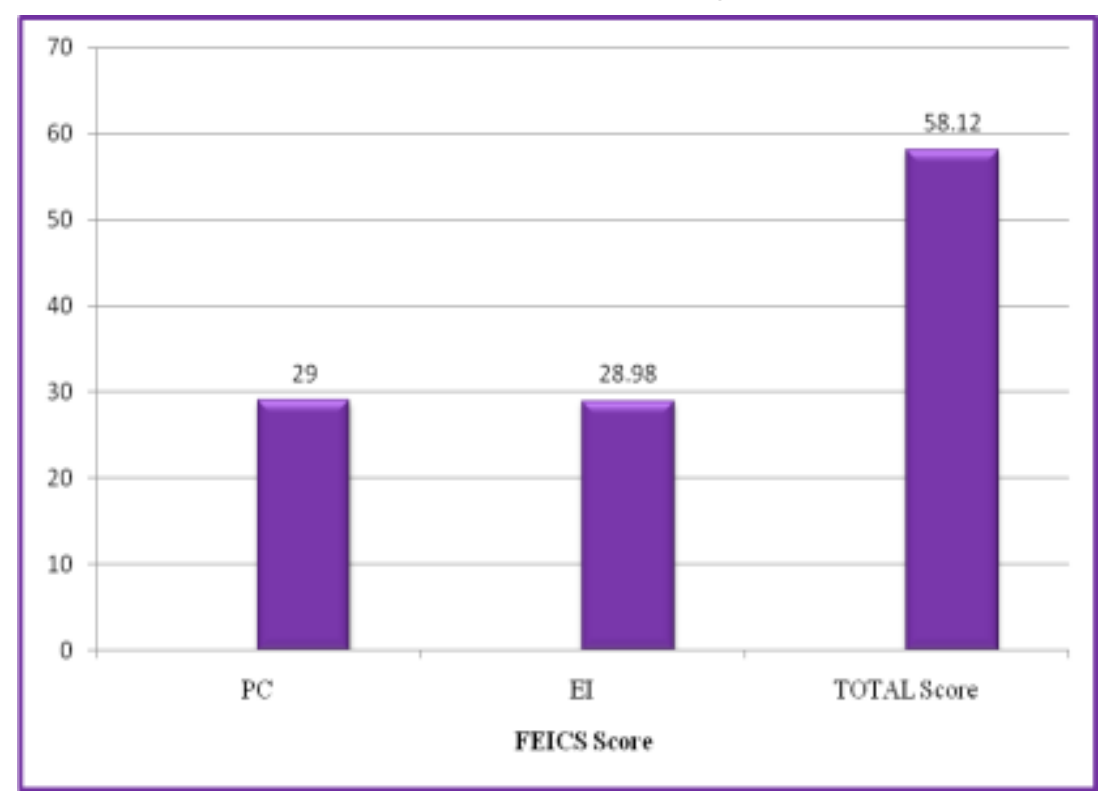

Figure 3: Clustered column chart shows FEICS scale and sub scale score among the caregivers.

4.3: Major findings of Table- 3 and Fig. 3 shows the PC score among the caregivers was 29 and the EI score was 28.98 and the total FEICS score was 58.12 which shows majority of the caregivers were in severe category with high EE. 
Table-4: FEICS sub scale score as per severity among the caregivers $n=100$

\begin{tabular}{|l|c|c|c|}
\hline PC Scale & Total score 35 & Category & Number of caregivers \\
\hline & 0 to1 1 & Mild & 0 \\
\hline & 12 to 23 & Moderate & 2 \\
\hline & 24 to 35 & Severe & 98 \\
\hline EI Scale & Total score 35 & Category & Number of caregivers \\
\hline & 0 to1 1 & Mild & 0 \\
\hline & 12 -to 23 & Moderate & 3 \\
\hline & 24 to35 & Severe & 97 \\
\hline
\end{tabular}

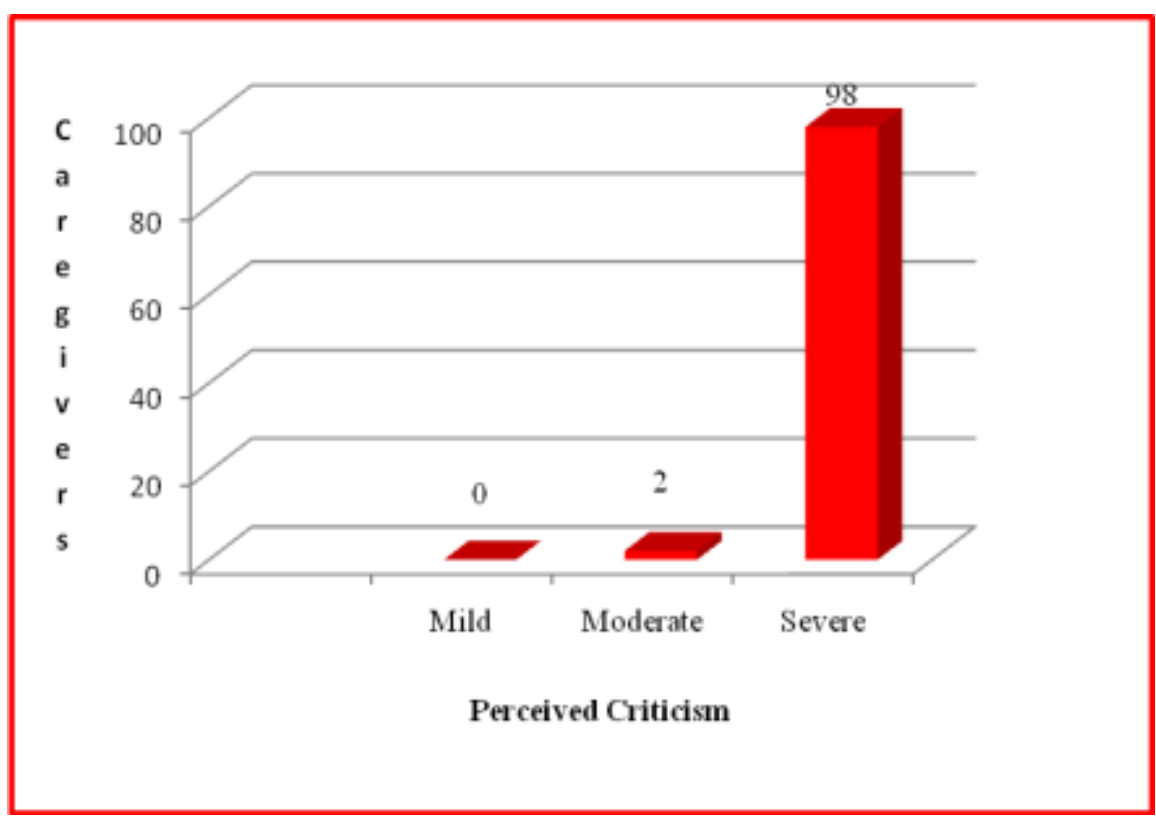

Figure 4: 3-D clustered column chart shows Perceived criticism score as per severity among the caregivers

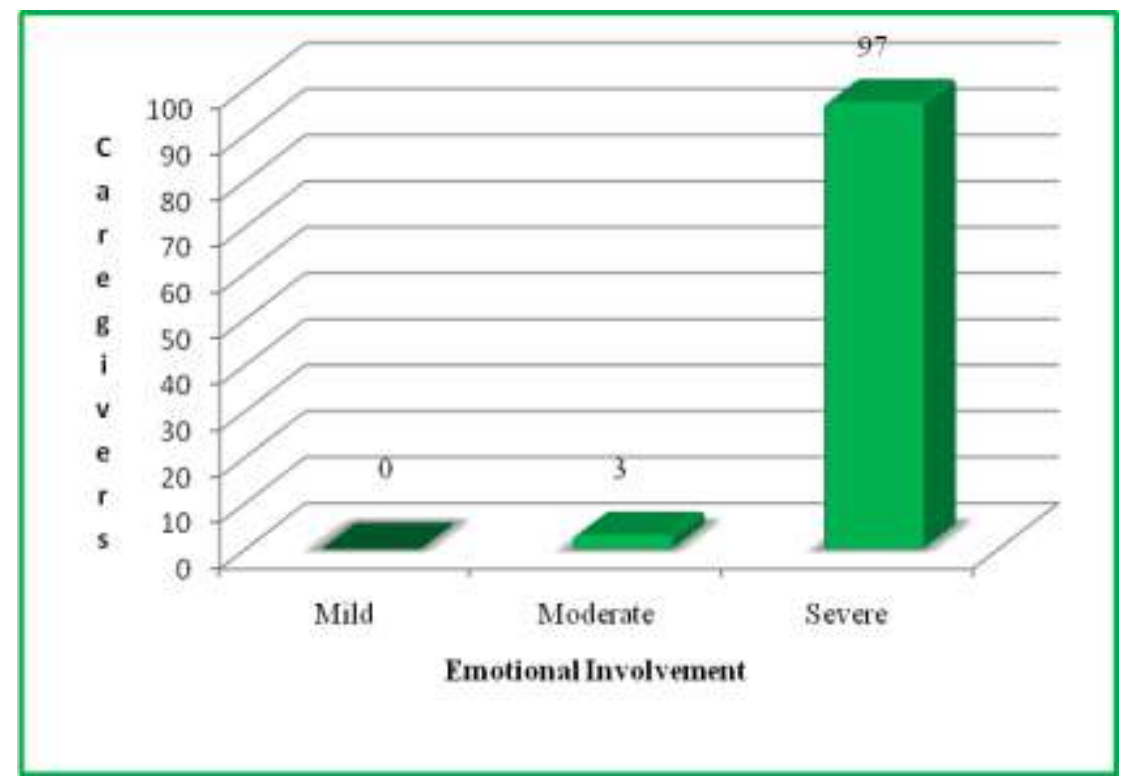

Figure -5: 3-D clustered column chart shows Emotional involvement score as per severity among the caregivers.

4.4 Table 4, Fig: 4 \& Fig: 5 show FEICS subscale wise score as per severity among the caregivers. Perceived criticism scale shows 98 caregivers had severe perceived criticism (PC) score whereas 97 caregivers had severe Emotional Involvement (EI) score which shows majority of the caregivers had high Expressed Emotions. 


\subsection{Association between demographic factors and Expressed Emotions}

Various demographic factors and their association to EE in caregivers were calculated. For all the demographic factor results the calculated value is less than tabulated value, so there is no association found between selected demographic variables and $\mathrm{EE}$ of the caregivers.

\section{Discussion}

This study was conducted with an objective to explore the level of EE among caregivers of patients with mental illness by recruiting 100 caregivers and the results show that majority of the caregivers of patients with mental illness had high Expressed Emotions.

Despite the differences in the language, culture or country, care giving has become everyday part of life for millions of people around the globe. It is invisible yet valuable care. It is essential that researchers around the world continue to explore the link between care giving and its impact on a carers' emotional and physical health

High EE is proven to be a significant family stressor resulting from relationship problems among the caregivers and patients with mental illness which is also a strong predictor of schizophrenia course. Hence, the family focused psychosocial interventions primarily emphasize on reducing the levels of EE of caregivers by enhancing their knowledge about the illness.

Cross cultural research on EE was conducted in diverse countries such as Australia, Germany, Denmark, Italy and India. Despite the cultural differences in defining and interpreting the terms like criticism, hostility and emotional over involvement, the EE research across cultures showed a definite trend. ${ }^{11}$

\subsection{Limitations of the Study:}

- It was limited to the the caregivers who were attending the psychiatric wards of selected tertiary care hospital of Nagpur which may not be the true representative of the entire population of the caregivers. Confirmation is therefore needed for more diverse and large group of caregivers with further longitudinal follow up.

- Self reporting has its own limitations due to element of subjectivity. The personal nature of the questions may make the caregivers reluctant to answer fully.

\subsection{Implications of the study:}

- This study has implications in enhancing the coping abilities of the caregivers and reducing their stresses by various ways like offering care giving classes and forming caregivers' support group.

- It appears critical to improve and increase services and resources to support care giving. It is also essential to educate and ensure that the people affected know how to use the available resources.

- The brief and inexpensive psycho social interventions would be useful and feasible for health care provider and reduce revolving door phenomena among the patients which is associated with caregivers' high Expressed Emotions.

\subsection{Recommendations:}

- Further studies with larger sample sizes and longer follow up periods are needed in this regards.

- Further research is required into identifying the people at risk, the causes, course of illness and exploring effective intervention strategies.

- A comparative study of several types of brief interventions or alternatively a qualitative investigation of what aspects of the intervention the caregivers find most beneficial in controlling their EE.

- More attention should be directed to study the early detection of mental illness and the influences of environmental factors.

- Future research should also help to better understand stigma, religious belief and involve community leaders in strengthening mental health services.

\section{Conclusion}

The current study highlights that caring for a person with mental illness can develop high expressed emotions and negative emotional atmosphere among the caregivers of patients with mental illness, which causes not only relapse and revolving door syndrome but also puts it impact on the course of illness. Hence, the family intervention approach which should manage the patient and family in all dimensions. It also helps the caregivers in lowering their expressed emotions, perceived burden of disease and enhancement in their coping strategy. 


\section{Acknowledgement}

Our gratitude goes to the patients and caregivers without whom this research project could not have been completed. Our sincere thanks to the Deans, Heads of department and Nursing staff of selected Government Medical College and Hospital, Nagpur for granting permission and extending support to conduct this study. The authors sincerely extend thanks to Dr. Anagha Nasery, Head of the department of statistics, Dharampeth M.P.Deo Memorial Science College, Nagpur and Mr. Suresh Morey, Assistant professor cum statistician, Department of Community Medicine, Govt. Medical College and Hospital Nagpur for all the statistical analysis and support.

Financial implications: Self funded.

Conflict of interest : None

\section{References}

[1]. Anekal. C, Amresha and Ganesan Venkatsubramanium.Expressed emotions in Schizophrenia An overview Indian Journal of Psychological Medicine . 2012 Jan-Mar;34(1):12-20

[2]. Reinhard S, Brooks-Danso A, Kelly K and Mason D. State of the Science: Professional Partners Supporting Family Caregiver American Journal of Nursing. 2008 September; 108 (Suppl 9): 28 -34.

[3]. Ogbolu RE, Adeyemi JD, Erinfolami AR.Expressed emotion among schizophrenic patients in Lagos, Nigeria: a pilot study. African Journal of Psychiatry.2013; 16:329-331.

[4]. Nations for Mental Health: Schizophrenia and Public Health.[Online] World Health Organization, 1996 [2013 November 23]; [55]. Available from:URL:http://www.who.int/mental health/media/en/55.

[5]. World development Report. Investing in health, published for the World Bank. Oxford University Press. 1993. [Cited 2013 January 17].

[6]. National Alliance on Mental Illness: SchizoaffectiveDisorder. [Online].2010[2014June7];Available from: URL:http://www.nami.org/Template.cfm?Section=By_Illness\&template=/ContentManagement/ContentDisplay.cfm\&ContentID=1 1837

[7]. National Institute of Health and Care Excellence. Psychosis and schizophrenia in adults: treatment and management guideline update. London: NICE; 2014.

[8]. Mathew Varghese, Anisha Shah , Udaya Kumar G S, Murali T, Isabel M P. Family intervention and support in schizophrenia A Manual on Family Intervention for the Mental Health Professional. WHO/ NIMHANS, Version 2, August 2002

[9]. Zubin, J. and Spring B (1977) Vulenerability:A New View on Schizophrenia Journal of Abnormal Psychology 86,103-126

[10]. Shinde S.P. Short term effect of family Psycho education in Schizophrenia. Unpublished Dissertation.MD (Psychiatry), NIMHANS, Bangalore. 2005.

[11]. Francis A. \& Papageorgiou P. Expressed emotion in Greek versus Anglo-Saxon families of individuals with schizophrenia. Australian Psychologist. 2004; 39 (2): 172-177. 